\title{
GAMBARAN STATUS JARINGAN PERIODONTAL PADA PELAJAR DI SMA NEGERI 1 MANADO
}

\author{
${ }^{1}$ Pieter Levinus Suling, ${ }^{2}$ Kustina Zuliari, ${ }^{3}$ Majesty Eunike Slat \\ ${ }^{1}$ Fakultas Kedokteran \\ ${ }^{2}$ Program Studi Kedokteran Gigi \\ ${ }^{3}$ Mahasiswa Program Studi Kedokteran Gigi \\ Fakultas Kedokteran Universitas Sam Ratulangi
}

\begin{abstract}
ABSTRAK
Pelajar pada masa remaja berada dalam masa bertumbuh menjadi dewasa. World Health Organization (WHO) menetapkan sekolah dan remaja dijadikan sebagai kelompok target yang penting untuk dilakukan pemeriksaan dan promosi kesehatan rongga mulut. World Health Organization (WHO) juga merekomendasikan usia untuk pemeriksaan kesehatan rongga mulut, yaitu usia 12 dan 15 tahun. Tujuan dari penelitian ini ialah untuk mengetahui gambaran status jaringan periodontal pada pelajar di SMA Negeri 1 Manado.

Penelitian ini merupakan penelitian deskriptif dengan pendekatan potong lintang (crosssectional). Sampel penelitian terdiri atas 226 pelajar yang berusia 15-16 tahun, terdiri atas 84 laki-laki dan 142 perempuan. Sampel diperoleh dengan menggunakan metode simple random sampling. Pemeriksaan dilakukan menggunakan kaca mulut dan WHO periodontal examining probe. Kondisi jaringan periodontal dan distribusi frekuensinya dievaluasi dengan indeks Community Periodontal Index of Treatment Needs (CPITN) dan digambarkan berdasarkan indeks CPITN.

Dalam penelitian ini terdapat 38 orang $(16,8 \%)$ memiliki jaringan periodontal sehat (skor 0 ), 6 orang $(2,7 \%)$ mengalami perdarahan gingiva tidak disertai kalkulus (skor 1), 169 orang $(74,8 \%)$ mengalami perdarahan gingiva disertai kalkulus (skor 2), 13 orang $(5,7 \%)$ memiliki poket periodontal 3,5-5,5 $\mathrm{mm}$ (skor 3), dan tidak ada yang memiliki poket periodontal lebih dari $5,5 \mathrm{~mm}$.
\end{abstract}

Kata kunci: Pelajar, status jaringan periodontal, CPITN

\section{ABSTRACT}

A student in adolescence phase is in the period when someone develops into an adult. World Health Organization (WHO) declared that schools and adolescents as important target group for examination and oral health promotion. World Health Organization (WHO) recommended 12 and 15 years old as important age groups for oral health examination. The research was aimed to describe the periodontal status of students in SMA Negeri 1 Manado.

This research was a descriptive study with cross-sectional study approach. The research samples consisted of 226 subjects, age range between 15-16, consisted of 84 males and 142 females. Samples were selected through simple random sampling. Flat dental mirror and WHO periodontal examining probe were used in this study. Periodontal condition and frequency distribution were evaluated using Community Periodontal Index of Treatment Needs (CPITN) and reported according to CPITN.

In this research only 16,8\% of subjects demonstrated a healthy periodontal status. Bleeding without calculus was noted in 2,7\% of subjects and bleeding with calculus had the highest score (74,8\%). Shallow pocket was found in 5,7\% and none of subjects had deep pocket. Keywords: Student, periodontal status, CPITN.

Korespondensi: Majesty Eunike Slat, Program Studi Kedokteran Gigi, Fakultas Kedokteran Universitas Sam Ratulangi, Manado, Indonesia. E-mail: majestyeunike09@gmail.com 


\section{PENDAHULUAN}

Pelajar pada masa remaja berada dalam masa bertumbuh menjadi dewasa atau tumbuh untuk mencapai kematangan. ${ }^{1}$ Seperlima dari penduduk dunia ialah remaja, yang didefinisikan oleh World Health Organization (WHO) sebagai orang yang berada dalam rentang usia 10 sampai 19 tahun. Remaja yang memiliki rasa percaya diri yang tinggi dan kemampuan sosial yang baik, akan menghargai dirinya sehingga mampu membuat keputusan yang baik mengenai kesehatan tubuhnya. ${ }^{2}$ Kesehatan rongga mulut yang mencakup kesehatan gigi dan jaringan periodontal merupakan hal penting bagi kesehatan dan kesejahteraan tubuh secara umum serta memengaruhi kualitas kehidupan, termasuk fungsi bicara, pengunyahan, dan rasa percaya diri. $^{3}$

Status jaringan periodontal dipengaruhi oleh faktor primer dan sekunder. Faktor primer berupa bakteri sedangkan faktor sekunder terdiri atas faktor lokal maupun sistemik. ${ }^{4}$ Status jaringan periodontal diukur oleh suatu indeks yang disebut Community Periodontal Index of Treatment Needs (CPITN). Indeks pengukuran ini merupakan indeks resmi yang digunakan oleh WHO untuk mengukur kondisi jaringan periodontal serta perkiraan kebutuhan perawatannya. ${ }^{3}$

WHO menetapkan sekolah dan remaja dijadikan sebagai kelompok target yang penting untuk dilakukan pemeriksaan dan promosi kesehatan rongga mulut. ${ }^{5}$ WHO juga merekomendasikan usia untuk pemeriksaan kesehatan rongga mulut, yaitu usia 12 dan 15 tahun. $^{6,7}$ Usia tersebut direkomendasikan sebagai usia untuk pemeriksaan karena gigi tetap yang menjadi gigi indeks CPITN telah bertumbuh seutuhnya. ${ }^{8}$

Hasil penelitian WHO pada beberapa negara dunia menunjukkan bahwa penyakit periodontal seperti periodontitis berat ditemukan pada $5-15 \%$ dari populasi. ${ }^{2,9,10}$ Keadaan jaringan periodontal pada pelajar di Iran ialah $14,5 \%$ memiliki jaringan periodontal yang sehat, $33,7 \%$ mengalami perdarahan gingiva, dan ditemukan kalkulus pada $48,7 \%$ sampel, berdasarkan penelitian pada tahun 2005. ${ }^{11}$ Prevalensi penyakit periodontal di Indonesia menunjukkan hasil $60 \%$ berdasarkan Survei Kesehatan Rumah Tangga tahun 2004. ${ }^{12}$ Keadaan jaringan periodontal pada pelajar di kabupaten Sinjai ialah $11,8 \%$ yang memiliki jaringan periodontal yang sehat, 4,6\% mengalami perdarahan gingiva, dan ditemukan kalkulus pada 70,3\% sampel, berdasarkan penelitian tahun $2007 .^{13}$

Berdasarkan latar belakang di atas, penulis tertarik melakukan penelitian untuk mengetahui gambaran status jaringan periodontal pada pelajar di SMA Negeri 1 Manado. Penelitian dilakukan di SMA Negeri 1 Manado dengan alasan bahwa sekolah ini memiliki pelajar dengan jumlah terbanyak di kota Manado, berdasarkan data Dinas Pendidikan Nasional kota Manado, sehingga dapat ditemukan karakteristik pelajar yang beragam, serta berdasarkan survei awal yang dilakukan, di sekolah ini belum pernah diadakan penelitian mengenai status jaringan periodontal pada para pelajar.

Penelitian ini bertujuan ntuk mengetahui gambaran status jaringan periodontal pada pelajar di SMA Negeri 1 Manado.

\section{BAHAN DAN METODE}

Metode yang digunakan pada penelitian ini merupakan penelitian deskriptif dengan pendekatan potong lintang (crosssectional). Populasi pada penelitian ini ialah seluruh pelajar di SMA Negeri 1 Manado berusia 15-16 thn yang berdasarkan survei awal berjumlah 521 orang. ${ }^{14}$ Sampel penelitian diperoleh dengan menggunakan rumus slovin. Sampel penelitian terdiri atas 226 pelajar yang berusia 15-16 tahun, terdiri atas 84 laki-laki dan 142 perempuan. Metode pengambilan sampel yang digunakan ialah simple random sampling. Sampling frame terdiri atas kriteria inklusi dan eksklusi.

Pemeriksaan dilakukan menggunakan kaca mulut dan WHO examining probe. Kondisi jaringan periodontal dan distribusi frekuensinya dievaluasi dengan indeks Community Periodontal Index of Treatment Needs (CPITN) dan digambarkan 
berdasarkan indeks CPITN pada rongga mulut yang telah dibagi menjadi enam sektan dan telah ditentukan gigi indeks untuk dilakukan pemeriksaan. Kegunaan utama CPITN ialah mengukur kebutuhan perawatan penyakit periodontal dan juga merekomendasikan jenis perawatan yang dibutuhkan untuk mencegah penyakit periodontal. ${ }^{15}$ Skor pemeriksaan CPITN yang menunjukkan keadaan jaringan periodontal ialah sebagai berikut:

1. Skor 0: Di sulkus yang paling dalam pada suatu sektan, area berwarna pada probe masih terlihat lengkap. Gingiva sehat dan tidak menunjukkan perdarahan pada probing. Tidak ditemukan kalkulus.

2. Skor 1: Area berwarna masih terlihat lengkap di sulkus yang terdalam pada suatu sektan, tidak ditemukan kalkulus tetapi dijumpai perdarahan setelah dilakukan probing ringan.

3. Skor 2: Area berwarna masih terlihat lengkap di sulkus yang terdalam pada suatu sektan, dapat ditemukan perdarahan setelah dilakukan probing, dan ditemukan kalkulus supra atau subgingiva.

4. Skor 3: Area berwarna pada probe masuk sebagian ke dalam sulkus. Hal ini menunjukkan adanya poket dangkal dengan kedalaman lebih dari $3,5 \mathrm{~mm}$ tapi kurang dari 5,5 mm.

5. Skor 4: Area berwarna pada probe sudah masuk semuanya ke dalam poket, menunjukkan kedalaman poket sudah lebih dari 5,5 $\mathrm{mm}$.

Penelitian diawali dengan meminta persetujuan melakukan penelitian dengan mengisi lembar informed consent. Setelah didapat persetujuan, maka pemeriksaan dalam penelitian dimulai. Pemeriksaan dilakukan langsung secara tim di SMA Negeri 1 Manado. Pemeriksaan dilakukan secara bergilir pada setiap pelajar yang termasuk dalam kriteria inklusi. Pelajar akan diperiksa satu persatu dengan memanggil nama sesuai nomor urut yang telah ditentukan.

\section{HASIL}

Tabel 1. Distribusi Subjek Penelitian Berdasarkan Jenis Kelamin

\begin{tabular}{ccc}
\hline Jenis Kelamin & Jumlah (n) & $\begin{array}{c}\text { Persentase } \\
(\%)\end{array}$ \\
\hline Laki-laki & 84 & 37.2 \\
Perempuan & 142 & 62.8 \\
Total & 226 & 100.0 \\
\hline
\end{tabular}

Tabel 2. Distribusi Subjek Penelitian Berdasarkan Usia

\begin{tabular}{ccc}
\hline $\begin{array}{c}\text { Usia } \\
\text { (Tahun) }\end{array}$ & Jumlah (n) & $\begin{array}{c}\text { Persentase } \\
(\%)\end{array}$ \\
\hline 15 & 157 & 69.5 \\
16 & 69 & 30.5 \\
Total & 226 & 100.0 \\
\hline
\end{tabular}

Tabel 3. Distribusi Status Jaringan Periodontal Pelajar Usia 15-16 tahun Berdasarkan Pengukuran CPITN

\begin{tabular}{llll}
\hline Kondisi Jaringan Periodontal & Skor CPITN & $\begin{array}{c}\text { Jumlah } \\
(\mathrm{n})\end{array}$ & $\begin{array}{c}\text { Persentase } \\
(\%)\end{array}$ \\
\hline Sehat & 0 & 38 & 16.8 \\
Perdarahan gingiva tidak disertai kalkulus & 1 & 6 & 2.7 \\
Perdarahan gingiva disertai kalkulus & 2 & 169 & 74.8 \\
Poket periodontal 3,5-5,5 mm & 3 & 13 & 5.7 \\
Poket periodontal $>5,5 \mathrm{~mm}$ & 4 & - & - \\
& Total & 226 & 100.0 \\
\hline
\end{tabular}


Tabel 4. Distribusi Status Jaringan Periodontal dari Skor CPITN Tertinggi Berdasarkan Jenis Kelamin

\begin{tabular}{llccccc}
\hline \multirow{2}{*}{ Kondisi Jaringan Periodontal } & \multirow{2}{*}{ Skor } & \multicolumn{4}{c}{ Jenis Kelamin } \\
\cline { 3 - 6 } & CPITN & \multicolumn{2}{c}{ Laki-laki } & \multicolumn{2}{c}{ Perempuan } \\
& & $\mathrm{n}$ & $\%$ & $\mathrm{n}$ & $\%$ \\
\hline Sehat & 0 & 15 & 6.6 & 23 & 10.2 \\
Perdarahan gingiva tidak disertai kalkulus & 1 & 2 & 0.8 & 4 & 1.9 \\
Perdarahan gingiva disertai kalkulus & 2 & 63 & 27.9 & 106 & 46.9 \\
Poket periodontal 3,5-5,5 mm & 3 & 4 & 1.9 & 9 & 3.8 \\
Poket periodontal $>5,5 \mathrm{~mm}$ & 4 & - & - & - & - \\
& Total & 84 & 37.1 & 142 & 62.9 \\
\hline
\end{tabular}

\section{PEMBAHASAN}

Hasil penelitian menunjukkan bahwa ada pelajar yang memiliki jaringan periodontal sehat, walaupun tidak dalam jumlah yang banyak yaitu 38 orang $(16,8 \%)$. Hal ini sesuai dengan penelitian yang dilakukan A. Gani (2007) pada remaja di kabupaten Sinjai yang menunjukkan bahwa jaringan periodontal sehat terdapat pada $11,8 \%$ subjek penelitian. ${ }^{13}$ Penelitian yang dilakukan oleh AS Sanei, A. Nikbakht-Nasrabadi (2005) pada remaja di Iran juga menunjukkan bahwa jaringan periodontal sehat terdapat pada $14,5 \%$ subjek penelitian. Hasil penelitian ini menunjukkan bahwa masih rendahnya jumlah subjek penelitian yang memiliki status jaringan periodontal sehat. Hal ini menunjukkan masih jauhnya hasil penelitian ini dari target yang ditetapkan oleh WHO pada tahun 2010 yaitu 100\% dari semua orang berusia 15 tahun yang termasuk dalam important age group, memiliki jaringan periodontal yang sehat dimana terdapat 5-6 sektan pemeriksaan CPITN yang sehat. ${ }^{11}$

Hasil penelitian juga menunjukkan bahwa banyak pelajar yang mengalami perdarahan gingiva disertai kalkulus yaitu 169 orang $(74,8 \%)$. Hasil penelitian ini sesuai dengan penelitian yang dilakukan pada remaja di kabupaten Sinjai yang menunjukkan bahwa 70,3\% subjek penelitian mengalami perdarahan gingiva disertai kalkulus. ${ }^{13}$ Alasan untuk tingginya jumlah subjek penelitian yang mengalami perdarahan gingiva disertai kalkulus (skor 2) dapat dihubungkan dengan rendahnya kebersihan rongga mulut (oral hygiene). ${ }^{11}$
Hasil penelitian yang menunjukkan bahwa perdarahan gingiva disertai kalkulus pada pelajar usia 15-16 tahun sesuai dengan teori yang menyatakan bahwa penyakit periodontal terjadi karena adanya faktor primer berupa iritasi bakteri dan faktor sekunder berupa faktor lokal dan sistemik. Faktor lokal dapat berupa: restorasi yang keliru, kavitas karies, tumpukan sisa makanan, geligi tiruan yang desainya tidak baik, alat ortodonti, susunan gigi-geligi yang tidak teratur, kurangnya seal bibir atau kebiasaan bernafas melalui mulut, dan merokok. Faktor sistemik dapat berupa: faktor genetik, nutrisional, hormonal, dan hematologi (penyakit darah). Pada pelajar usia 15-16 tahun faktor sistemik yang dapat memengaruhi kondisi jaringan periodontal ialah faktor hormonal. Perubahan hormonal yang berlangung pada masa pubertas dapat menimbulkan perubahan jaringan gingiva yang mengubah respon terhadap bakteri atau produk-produk plak. Perubahan hormonal pada masa pubertas dapat menyebabkan inflamasi yang hebat yang diikuti dengan pembengkakan dan perdarahan gingiva. ${ }^{4}$

Kalkulus merupakan suatu massa yang mengalami kalsifikasi, terbentuk dan melekat erat pada permukaan gigi, dan objek solid lainnya di dalam mulut, misalnya restorasi dan gigi-geligi tiruan. Kalkulus jarang ditemukan pada gigi susu dan tidak sering ditemukan pada gigi permanen anak. Meskipun demikian, pada anak usia 9 tahun, kalkulus sudah dapat ditemukan pada sebagian besar rongga mulut, dan pada hampir seluruh rongga mulut individu dewasa. Berdasarkan hubungannya terhadap gingival margin, 
kalkulus dikelompokkan menjadi kalkulus supragingival dan subgingival. Kalkulus supragingival ialah kalkulus yang melekat pada permukaan mahkota gigi mulai dari puncak gingival margin dan dapat dilihat. Kalkulus subgingival ialah kalkulus yang berada di bawah batas gingival margin, biasanya pada daerah saku gusi dan tidak dapat terlihat pada waktu pemeriksaan, biasanya padat dan keras, warnanya cokelat tua atau hijau kehitam-hitaman, konsistensinya seperti kepala korek api, dan melekat erat ke permukaan gigi. Kalkulus banyak terdapat pada bagian bukal molar rahang atas yang berhadapan dengan duktus Stensen's, pada bagian lingual gigi depan rahang bawah yang berhadapan dengan duktus Wharton's, dan juga pada gigi yang sering tidak digunakan. ${ }^{3}$

Hasil penelitian menunjukkan bahwa paling banyak pelajar mengalami perdarahan gingiva disertai kalkulus sehingga kebutuhan perawatan yang dibutuhkan ialah skeling. Skeling merupakan proses membuang plak dan kalkulus dari permukaan gigi, baik supragingiva dan subgingiva. Tujuannya ialah untuk mengembalikan kesehatan gusi dengan cara membuang semu elemen yang menyebabkan radang gusi (plak, kalkulus, endotoksin) dari permukaan gigi. ${ }^{3}$

Hasil penelitian menunjukkan bahwa yang paling banyak ditemukan pada subjek penelitian perempuan yaitu perdarahan gingiva disertai kalkulus, sebanyak 106 orang $(46,9 \%)$. Hal ini bertolak belakang dengan penelitian yang dilakukan oleh AS Sanei, A. Nikbakht-Nasrabadi (2005) pada remaja di Iran yang menunjukkan bahwa kalkulus ditemukan lebih banyak pada subjek penelitian laki-laki yaitu $51,2 \% .^{11}$ Kalkulus yang lebih banyak ditemukan pada subjek penelitian perempuan daripada subjek penelitian laki-laki dapat diteliti lebih lanjut mengenai hubungannya dengan hormonal maupun kebiasaan menjaga kebersihan rongga mulut.

Hasil penelitian juga menunjukkan bahwa jumlah subjek penelitian perempuan yang memiliki status jaringan periodontal sehat lebih banyak daripada subjek penelitian laki-laki. Hasil penelitian ini sesuai dengan penelitian yang dilakukan di
Udaipur, India (2012) yang menunjukkan bahwa subjek penelitian perempuan memiliki status jaringan periodontal sehat lebih banyak daripada subjek penelitian laki-laki. ${ }^{16}$ Alasan mengapa jenis kelamin bisa memengaruhi status jaringan periodontal bisa dikaitkan dengan kebiasaan dan kecenderungan perempuan yang dapat menjaga kebersihan rongga mulutnya lebih baik daripada laki-laki. ${ }^{11}$ Namun jika dilihat dari hasil penelitian ini, jenis kelamin tidak terlalu berpengaruh dalam menentukan status jaringan periodontal. Sehat atau tidaknya jaringan periodontal seseorang lebih dipengaruhi oleh keadaan oral hygiene atau kebersihan rongga mulut dan cara memeliharanya.

\section{SIMPULAN}

1. Status jaringan periodontal berdasarkan pengukuran CPITN pada hasil penelitian ini menunjukkan bahwa 169 orang $(74,8 \%)$ mengalami perdarahan gingiva disertai kalkulus, 38 orang $(16,8 \%)$ memiliki jaringan periodontal sehat, 6 orang $(2,7 \%)$ mengalami perdarahan gingiva tidak disertai kalkulus, 13 orang $(5,7 \%)$ memiliki poket periodontal 3,5-5,5 $\mathrm{mm}$, dan tidak ada yang memiliki poket periodontal lebih dari $5,5 \mathrm{~mm}$.

2. Kebutuhan perawatan yang dibutuhkan berdasarkan angka tertinggi pengukuran CPITN pada hasil penelitian ini ialah skeling.

\section{SARAN}

1. Institusi kesehatan diharapkan mengadakan kerja sama dengan pihak sekolah di bidang Usaha Kesehatan Gigi Sekolah (UKGS) agar dapat meningkatkan promosi kesehatan gigi dan mulut pada pelajar SMA berupa penyuluhan mengenai peningkatan dan perbaikan kesehatan gigi dan mulut secara teliti seperti mencegah terjadinya kalkulus serta membersihkan kalkulus atau karang gigi.

2. Perlu dilakukan penelitian lanjutan untuk melihat hubungan status jaringan periodontal berdasarkan pengukuran CPITN dengan jenis kelamin dan usia pelajar SMA. 


\section{DAFTAR PUSTAKA}

1. Ali M, Asrori M. Psikologi remaja. Jakarta: Bumi Aksara. 2009; h. 5

2. Petersen PE. The world oral health report 2003. [online] 2003. [cited 2013 July 11]. Available from: URL: http://www.who.int/entity/oral_health/ media/en/orh reports03 en.pdf

3. Putri MH, Herijulianti E, Nurjannah N. Ilmu pencegahan penyakit jaringan keras dan jaringan pendukung gigi. Jakarta: Buku Kedokteran EGC. 2010; h. 25-52, 205-209, 150

4. Madson JD, Eley. Buku ajar periodonti. Jakarta: Hipokrates. 2012; h. 1-19, 150, 205-209

5. World Health Organization. Important target groups. [online] 2013 [cited 2013 July 13]. Available from: URL: http://www.who.int/oral_health/action/ groups/en/

6. Hipermath SS. Textbook of preventive and community dentistry. New Delhi: Elsevier. 2007; p. 122, 176

7. Pintauli S, Taizo H. Menuju gigi dan mulut sehat, pencegahan dan pemeliharaan. USU Press. [serial online] 2008 [cited 2013 July 13]. Available from: URL: http://usupress.usu.ac.id/Menuju\%20Gi gi\%20Gigi\%20dan\%20Mulut\%20Mulu t\%20Sehat\%20_Pencegahan\%20Pemeli haraan_Normal_bab\%201.pdf

8. Itjiningsih. Anatomi gigi. Jakarta: Buku Kedokteran EGC. 1991; h. 239

9. Ohshima M, Zhu L, Yamaguchi Y, Kikuchi M, Nakajima I, Langham CS, Lin W, Otsuka K, Komiyama K. Comparison of periodontal health status and oral health behavior between Japanese and Chinese dental students. Journal of Oral Science [serial online] 2009. [cited 2012 March 17]; 51(2): 275-281. Available from: URL: http;//www.ncbi.nlm.mih.gov/pubmed/ 19550097

10. Kazeko L. Assessment of periodontal status and treatment need in the population of Belarus. OHDMBSC [serial online] 2007. [cited 2012 March 17]; 5(1): 1-6. Available from: URL: http://www.oralhealth.ro/volumes/2006

/volume-1/v1-06-1.pdf

11. Sanei AS, Nikbakht-Nasrabadi A. Periodontal health status and treatment needs in Iranian adolescent population. Arch Iranian Med [serial online] 2005. [cited 2013 April 17]; 8(4): 290-294. Available from: URL: http;//www.ams.ac.ir/AIM/0584/0011.p df

12. Survei Kesehatan Rumah Tangga 2004. [online] Available from: URL: http://www.depkes.go.id/downloads/pr ofil/kalteng/narasi_profil5/narasi_profil 05/BAB\%20III_profil.doc

13. Gani A. Kebutuhan perawatan periodontal remaja di Kabupaten Sinjai. Journal of Dentofasial [serial online] 2007 [cited 2011 November 19]; 7(2): 1-6. Available from: URL: http://repository.unhas.ac.id/bitstream/h andle/123456789/2588/daftar\%20pusta ka.doc? sequence $=8$

14. SMA Negeri 1 Manado. [online] [cited 2013 July 23]. Available from: URL: http://sman1-manadokota.sch.id

15. Chriestedy R, Sari DS, Arina YMD. Tingkat kebutuhan perawatan periodontal berdasarkan kunjungan pasien di RSGM FKG Universitas Jember bulan Agustus 2009-Agustus 2010. Jember: Bagian Periodonsia Fakultas Kedokteran Gigi Universitas Jember. 2010; h. 1-7

16. R Nagarajappa, M Kenchappa, G Ramesh, S Nagarajappa, M Tak. Assessment of periodontal status and treatment needs among 12 and 15 years old school children in Udaipur, India. European Archives of Paediatric Dentistry [serial online] 2012 [cited 2013 September 11; 13(3): 132. Available from: URL: http://www.ncbi.nlm.nih.gov/m/pubme $\mathrm{d} / 22652210$ 